\title{
A Campanha COVID-19 na Unidade de Cuidados Intensivos Polivalente do Hospital CUF Infante Santo
}

\section{The COVID-19 Campaign at the Polyvalent Intensive Care Unit of Hospital CUF Infante Santo}

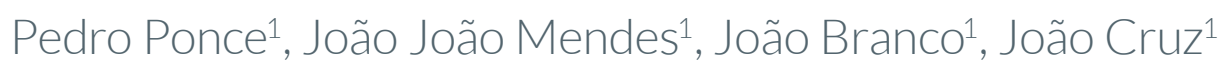

\section{RESUMO}

A atual pandemia de COVID-19 (doença clínica causada pelo SARS-CoV-2) teve disseminação mundial incluindo, desde 2 de março, Portugal. Por decisão de Conselho Executivo da José de Mello Saúde, interpretando o dever e a necessidade de cooperação com o Sistema Nacional de Saúde (SNS), foi decidido receber os seus beneficiários que procurassem os hospitais da rede, centrando toda a atividade COVID-19 da região Sul no Hospital CUF Infante Santo (HCIS). Apresentamos nesta narrativa todo o trabalho de preparação da infraestrutura, organização logística e resultados assistenciais da Unidade de Cuidados Intensivos Polivalente (UCIP) do HCIS desde o início a 23 de março até 30 de abril de 2020, numa homenagem a todos os que sem hesitações aderiram a esta aventura com o mesmo entusiasmo e espírito de serviço que sempre lhes conhecemos.

PALAVRAS-CHAVE: COVID-19; Unidades de Cuidados Intensivos 


\section{ABSTRACT}

The current COVID-19 pandemic (clinical disease caused by SARS-CoV-2) has spread worldwide including, since March 2nd, Portugal. By decision of the Executive Council of José de Mello Saúde, interpreting the duty and need for cooperation with the National Health System (SNS), it was decided to receive all patients presenting to our hospitals' network. All COVID-19 activity in the Center and South regions was referred to Hospital CUF Infante Santo (HCIS). We present in this narrative paper all our preparedness activity, preparing the infrastructure, logistical organization, patient management results of the HCIS General Intensive Care Unit (UCIP) from the beginning on March 23 to April 30, 2020, as a tribute to all those who without hesitation joined us on this adventure with their usual passion and resolve.

KEYWORDS: COVID-19; Intensive Care Units

\section{INTRODUÇÃO}

The greatest danger in times of turbulence, is not the turbulence, it is to act with yesterday's logic.

PETER DRUKER

A atual pandemia de COVID-19 (doença clínica causada pelo SARS-CoV-2) teve início na cidade de Wuhan (província chinesa de Hubei), com rápida disseminação na China e posteriormente envolvendo múltiplos países incluindo, desde 2 de março, Portugal. ${ }^{1}$ Embora o curso clínico da maioria dos doentes não seja grave e passível de tratamento ambulatório, cerca de 6\% a 10\% dos internados necessita de admissão a cuidados intensivos, predominantemente por insuficiência respiratória hipoxemiante. ${ }^{2,3}$ Numa série recente estes números sobem, com admissão em cuidados intensivos de 14,3\% dos doentes, dos quais a maioria com necessidade de ventilação mecânica invasiva (12,2\%) e elevada mortalidade (24,5\%), mantendo-se $72,7 \%$ em internamento e apenas 3,3\% já com alta. ${ }^{4}$

Por decisão de Conselho Executivo da José de Mello Saúde, interpretando o dever e a necessidade de cooperação com o Sistema Nacional de Saúde (SNS), foi decidido receber os seus beneficiários que procurassem os hospitais da rede, centrando toda a atividade COVID-19 da região Sul no Hospital CUF Infante Santo (HCIS).

Apresentamos nesta narrativa todo o trabalho de preparação da infraestrutura, organização logística e resultados assistenciais da Unidade de Cuidados Intensivos Polivalente (UCIP) do HCIS desde o início a 23 de março até 30 de abril de 2020, numa homenagem a todos os que sem hesitações aderiram a esta aventura com o mesmo entusiasmo e espírito de serviço que sempre Ihes conhecemos. They call us and we go. ${ }^{5}$

\section{PREPARAÇÃO DA UNIDADE ESTRUTURA, LOGÍSTICA E RECURSOS HUMANOS}

Apesar do primeiro internamento ter ocorrido a 23 março de 2020, a UCIP antecipou-se e preparou a sua organização funcional dias antes dessa admissão. Com base nas orientações definidas pela Direção Geral da Saúde e Ministério da Saúde, e indo ao encontro do delineado no Plano de Contingência da José de Mello Saúde para o doente crítico, foram definidos dois espaços distintos: para doentes COVID-19 negativos (4 camas no Recobro do Bloco Operatório 1) e para doentes COVID-19 positivos (12 camas no espaço da UCIP original). Destas 12 camas, duas são quartos fechados com pressão negativa (com adufa); um é um quarto de isolamento (sem pressão negativa) e 9 camas encontram-se em espaço aberto. Depois das devidas verificações e melhoramentos em termos de calafetagem de portas, janelas e encerramento de acessos, foi possível colocar em subpressão todo o espaço, salvaguardando o número de renovações de ar. Este ambiente foi testado previamente, sendo afinado pelas equipas técnicas do $\mathrm{HCIS}$, até à versão final de um espaço de cuidados único com primazia à segurança dos profissionais e doentes.

Paralelamente, foram deslocados para a zona contígua à UCIP todos os serviços de apoio à atividade: sistemas de informação à prática clínica (com redundância de equipamentos dentro e fora da unidade), farmácia (deslocação de toda a farmácia e reposição noturna) e logística (reinventando espaços de armazenamento com circuitos de reposição ajustados à nova realidade).

Todos os profissionais (médicos, enfermeiros, fisioterapeutas, auxiliares) a prestar cuidados na UCIP COVID-19 utilizam equipamentos de proteção indivi- 
TABELA 1. Estatística dos doentes admitidos na UCIP COVID-19 no período entre 23 de março e 30 de abril de 2020.

\begin{tabular}{|c|c|}
\hline IDADE & $67,2 \pm 10,2$ anos \\
\hline GÉNERO (MASCULINO) & $90 \%$ \\
\hline \multicolumn{2}{|l|}{ COMORBILIDADES } \\
\hline hipertensão arterial & $80 \%$ \\
\hline diabetes mellitus tipo 2 & $40 \%$ \\
\hline doença cardiovascular & $40 \%$ \\
\hline doença neurológica & $20 \%$ \\
\hline doença respiratória & $40 \%$ \\
\hline doença renal crónica & $20 \%$ \\
\hline doença neoplásica & $10 \%$ \\
\hline doença autoimune & $10 \%$ \\
\hline \multicolumn{2}{|l|}{ ORIGEM } \\
\hline Atendimento Permanente & $60 \%$ \\
\hline Enfermaria & $40 \%$ \\
\hline $\begin{array}{l}\text { DIAS DE EVOLUÇÃO DA DOENÇA } \\
\text { (À ADMISSÃO NA UCIP) }\end{array}$ & $9,4 \pm 2,4$ \\
\hline \multicolumn{2}{|l|}{ MOTIVO DE ADMISSÃO } \\
\hline insuficiência respiratória hipoxemiante & $100 \%$ \\
\hline $\mathrm{PAO}_{2} / \mathrm{FIO}_{2}$ (À ADMISSÃO NA UCIP) & $169 \pm 37,4$ \\
\hline \multicolumn{2}{|l|}{ FENÓTIPO PULMONAR (À ADMISSÃO) } \\
\hline fenótipo pulmonar L & $90 \%$ \\
\hline fenótipo pulmonar $\mathrm{H}$ & $10 \%$ \\
\hline \multicolumn{2}{|l|}{ SUPORTE VENTILATÓRIO* } \\
\hline $\begin{array}{l}\text { oxigenoterapia de alto fluxo por cânulas } \\
\text { nasais }\end{array}$ & $20 \%$ \\
\hline ventilação mecânica não invasiva & $30 \%$ \\
\hline $\begin{array}{l}\text { ventilação mecânica invasiva } \\
\text { (tempo de ventilação) }\end{array}$ & $\begin{array}{c}70 \% \\
(6,9 \pm 2,4 \text { dias })\end{array}$ \\
\hline PEEP máxima & $9,4 \pm 2,3$ \\
\hline \multicolumn{2}{|l|}{ TERAPÊUTICA ADJUVANTE } \\
\hline $\mathrm{ECCO}_{2}-\mathrm{R}$ & $10 \%$ \\
\hline ventral & $10 \%$ \\
\hline auto-ventral & $30 \%$ \\
\hline
\end{tabular}

OUTRA TERAPÊUTICA DE SUPORTE DE ÓRGÃO

\begin{tabular}{l|c}
\hline suporte vasopressor (noradrenalina) & $70 \%$ \\
\hline TERAPÊUTICA ESPECÍFICA & \\
\hline $\begin{array}{l}\text { antivirais } \\
\quad \text { hidroxicloroquina } \\
\quad \text { lopinavir/ritonavir }\end{array}$ & $100 \%$ \\
$\begin{array}{l}\text { corticoides } \\
\text { ANTIBIOTICOTERAPIA }\end{array}$ & $100 \%$ \\
\hline $\begin{array}{l}\text { antibioticoterapia empírica iniciada/mantida } \\
\text { (à admissão na UCIP) }\end{array}$ & $80 \%$ \\
\hline $\begin{array}{l}\text { antibioticoterapia empírica iniciada (durante } \\
\text { o internamento na UCIP) }\end{array}$ & \\
\hline $\begin{array}{l}\text { COMPLICAÇÕES } \\
\text { delirium }\end{array}$ & $20 \%$ \\
suporte transfusional & \\
\end{tabular}

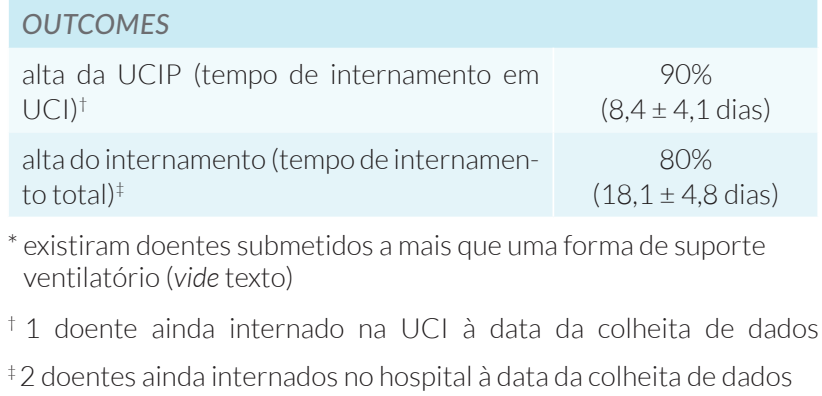

* existiram doentes submetidos a mais que uma forma de suporte ventilatório (vide texto)

† 1 doente ainda internado na UCl à data da colheita de dados

₹2 doentes ainda internados no hospital à data da colheita de dados

dual (EPIs) específico, descartável (uso único) e impermeável (sobre roupa descartável ou de uso único): fato de proteção integral (com capuz incorporado e proteção de pescoço), touca, máscara FFP2 (com adequado ajuste facial), proteção ocular (óculos com proteção lateral e viseira), duplo par de luvas (par interno sobre a pele, par externo como reforço da segurança), e proteção de calçado (perneiras sobre sapatos impermeáveis e de uso exclusivo nas áreas de isolamento).

Em função do número de pontos de acesso à UCIP para doentes COVID-19 positivos foram definidos 3 circuitos para: profissionais, doentes e sujos (lixos). Foi criada uma adufa de entrada de profissionais, que permitia a sua preparação com EPIs, bem como a sua retirada. Estes momentos foram sempre realizados sob observação ou colaboração de terceiros de forma a garantir que se efetuavam sem risco de contaminação.

O fluxo de doentes às unidades realiza-se em dois cenários: (1) doentes clinicamente sem critérios e com pelo menos 2 testes negativos são admitidos na unidade não COVID-19; e (2) doentes suspeitos ou confirmados por teste COVID-19 positivo são admitidos na unidade COVID-19, sendo colocados em quarto de isolamento de pressão negativa, onde se inicia/dá continuidade ao processo de cuidados com todos os procedimentos invasivos a serem realizados nessas condições (incluindo entubação orotraqueal). Os doentes com teste positivo, depois de estabilizados, são transferidos para a zona em espaço aberto. Os doentes suspeitos, ou são transferidos para o espaço aberto (por terem ulteriormente teste positivo para COVID-19), ou são transferidos para o quarto de isolamento/UCIP não COVID-19 após 2 testes negativos (se se mantém elevada suspeita clínica para COVID-19).

O circuito de sujos encontra-se segregado de todos os outros, com as devidas orientações a serem cumpridas: acomodação, higienização e transporte dos recipientes devidamente identificados.

A equipa médica habitual da unidade (7 elementos) não foi reforçada, cumprindo turnos de 8 ou 16 horas. A 
gestão de recursos de enfermagem e auxiliares em dois espaços físicos, obrigou a reajustar equipas e dotações, sendo planeado um modelo evolutivo de cobertura da atividade. E são as pessoas que interpretam estes modelos, a chave da resposta a situações de crise. Num cenário de grande imprevisibilidade, incerteza e receios, a garantia de continuidade dos processos de cuidados em turnos de 4 horas de permanência, com EPIs e com equipas partilhadas, faz-se pela disponibilidade e adaptação dos profissionais a esta nova realidade. Articulando-se por videochamada e intercomunicadores com a zona externa de apoio, o trabalho à tarefa está muito presente. O resultado final não depende só da soma das várias tarefas, mas essencialmente, de tudo o que cada profissional coloca de si em cada tarefa.

Conscientes do distanciamento e ausência de familiares/pessoas de referência no processo de cuidados, impossibilitados de entrar no hospital, procedemos à elaboração de um formulário de preenchimento diário, que gera um relatório anexo ao processo clínico. Concomitantemente a informação aí contida é partilhada telefonicamente com a família por um administrativo, num primeiro momento, complementada por um médico ou enfermeiro no período da tarde. Desta forma proativa na transmissão da informação clínica, procuramos também contribuir na humanização de cuidados de saúde.

\section{PREPARAÇÃO PARA ESCASSEZ DE RECURSOS}

A pandemia COVID-19 provocou a escassez de inúmeros bens e serviços, tais como soluções desinfetantes, máscaras e restantes EPIs para profissionais de saúde. Para mais, a evolução da pandemia em outros países fez prever que o número de casos de insuficiência respiratória aguda com necessidade de ventilação mecânica invasiva levasse a um desequilíbrio entre as necessidades e a disponibilidade de vagas. Neste cenário, a admissão a UCIP não poderia basear-se apenas na avaliação caso-a-caso (que inclui a perceção de gravidade por parte do clínico e a gestão global dos recursos disponíveis), mas antes numa avaliação global respeitando o princípio da justiça distributiva e garantindo a alocação apropriada de recursos.

Quando estabelecemos o nosso plano assistencial considerámos a possibilidade e criámos protocolos para um cenário extraordinário de catástrofe em que fosse necessário: (1) restringir a admissão a serviços de medicina intensiva a doentes com maior probabilidade de benefício; e (2) fazer limitação ou retirada da terapêutica ativa a doentes com elevada probabilidade de morte, que não melhorassem, ou se se deteriorassem.

\section{MÉTODOS}

Foram recolhidos os dados, através da consulta do processo informático (B-ICU.Care e Glintt), de todos os doentes internados na UCIP do HCIS no período compreendido entre 23 de março e 30 abril. Para a caracterização clínica foram recolhidos 16 fatores: idade, género, comorbilidades (hipertensão arterial, diabetes mellitus tipo 2, doença cardiovascular, doença neurológica, doença respiratória, doença renal crónica, doença neoplásica, doença autoimune), origem (Atendimento Permanente, Enfermaria), dias de evolução da doença (à admissão na UCIP), motivo de admissão, $\mathrm{PaO}_{2} / \mathrm{FiO}_{2}$ (à admissão na UCIP), fenótipo pulmonar (à admissão), suporte ventilatório [oxigenoterapia de alto fluxo por cânulas nasais (HFNO, high flow nasal oxygen), ventilação mecânica não invasiva (VNI), ventilação mecânica invasiva (incluindo tempo de ventilação)], PEEP máxima, terapêutica adjuvante (ECCO$-\mathrm{R}$, ventral, auto-ventral), outra terapêutica de suporte de órgão, nomeadamente substituição da função renal, terapêutica específica (antivirais, corticoides), antibioticoterapia, complicações, e outcomes (resultados) finais [alta da UCIP (tempo de internamento em UCI), alta do internamento (tempo de internamento total)]. As variáveis qualitativas foram expressas em percentagem, e as variáveis quantitativas são expressas como média \pm desvio padrão.

\section{RESULTADOS}

As características e outcomes dos doentes admitidos na UCIP COVID-19 no período entre 23 de março e 30 de abril de 2020 encontram-se resumidos na Tabela 1.

\section{CARACTERÍSTICAS}

Foram admitidos 10 doentes COVID-19 positivos (confirmados por real-time PCR) predominantemente do sexo masculino (90\%) e com idade média de 67,2 \pm 10,2 anos. Dos doentes admitidos, 90\% apresentava pelo menos uma comorbilidade, sendo a mais frequente hipertensão arterial (80\%), mas com um valor considerável de disfunções crónicas de órgão (40\% de insuficiência respiratória crónica e 40\% de doença renal crónica). A maioria dos doentes admitidos (60\%) proveio do Atendimento Permanente, opção espontânea, ou referenciação de outros hospitais do grupo, e o motivo de admissão foi em todos os casos insuficiência respiratória hipoxémica, com relação $\mathrm{PaO}_{2} / \mathrm{FiO}_{2}$ média de 169 \pm 37,4 (com fenótipo $\mathrm{H}$ mais frequente).

Em relação à terapêutica de suporte ventilatório: (1) 70\% necessitaram de ventilação mecânica invasiva (dos quais $10 \%$ foram submetidos a VNI pré-entubação e outros $10 \%$ submetidos a ventilação não invasiva-VNI 
pré e pós-entubação) com tempo médio de ventilação invasiva de 6,9 \pm 2,4 dias e PEEP mais elevada de 9,4 \pm 2,3; e (2) 30\% foram geridos exclusivamente com VNI ou HFNO associada a auto-ventral (doente assumia a posição de decúbito ventral a pedido da equipa).

Em relação a outras terapêuticas de suporte: (1) 70\% dos doentes tiveram necessidade de suporte vasopressor (com dose máxima média de 15,7 £ 9,0 mcg/min); e (2) um teve necessidade de $\mathrm{ECCO}_{2}$-R. Não existiu necessidade de outras técnicas de suporte de órgão, nomeadamente suporte depurativo renal.

Em relação à terapêutica específica antiviral: (1) apenas um doente realizou lopinavir/ritonavir; e (2) todos foram medicados com hidroxicloroquina, sendo que em 40\% dos casos foi interrompida por toxicidade (disritmia associada a prolongamento do intervalo QTc em três casos e diarreia em um caso).

Em relação à antibioticoterapia: (1) em 40\% dos casos foi iniciada/mantida antibioticoterapia empírica à admissão por suspeita de sobreinfeção bacteriana; e (2) em 20\% dos casos foi iniciada antibioticoterapia empírica por suspeita de sobreinfeção bacteriana adquirida da UCIP (em um caso de-escalada por isolamento microbiológico).

A maioria dos doentes (70\%) apresentou quadro de delirium (com necessidade de medicação com dexmedetomidina e/ou neurolépticos), e um doente teve necessidade de suporte transfusional (6 UCE e uma pool de plaquetas).

\section{OUTCOMES}

À data da recolha de dados (30 de abril) não se verificaram óbitos, com 90\% dos doentes com alta da UCIP (tempo de internamento em UCl de 8,4 \pm 4,1 dias) e $80 \%$ com alta hospitalar (tempo total de internamento de $18,1 \pm 4,8$ dias).

No período de avaliação foram admitidos outros 24 doentes que se revelaram COVID-19 negativos, sendo que seis foram admitidos como suspeitos na UCIP COVID-19 e posteriormente transferidos para a UCIP não COVID-19. Não se verificaram casos de infeção cruzada por SARS-CoV-2 entre doentes. Igualmente não ocorreram casos de infeção por SARS-CoV-2 entre profissionais de saúde.

\section{DICUSSÃO}

\section{GERAL}

A casuística dos doentes COVID-19 internados na UCIP do HCIS, embora pequena, é representativa. A idade mé- dia (67,2 \pm 10,2 anos) é superior à previamente descrita na China, ${ }^{2}$ Itália ${ }^{6}$ e Estados Unidos da América, ${ }^{7}$ mantendo-se a elevada prevalência de doentes do género masculino (90\%). A maioria dos doentes apresenta comorbilidades, com elevada prevalência de hipertensão arterial à semelhança do descrito em outras séries., 2,6,7

Como seria expectável num projeto fraturante, montado em curtíssimo espaço de tempo, sofremos consequências indesejáveis: (1) destruímos a dinâmica clássica e o fluir de cuidados nos circuitos hospitalares, tornando muito mais complexo e moroso todo o ato assistencial; (2) baixou o nível de vigilância e qualidade de cuidados que sempre praticámos (p.e. a logística do equipamento de proteção e a complexidade do circuito para chegar a um doente convidava a um telefonema para o enfermeiro em vez de voltarmos repetidamente à cabeceira do doente como sempre fizemos); (3) a imagem de hospital de guerra, barricado, onde deambulavam profissionais mascarados irreconhecíveis, assustou ainda mais doentes de outras patologias, principalmente os mais frágeis e idosos, que fugindo do risco infecioso morreram em casa ou chegaram tarde demais; e (4) o diagnóstico diferencial passou a ser dicotómico, COVID-19 positivo ou COVID-19 negativo, adquirindo estes últimos um estigma de doentes de segunda. ${ }^{8}$

\section{TERAPÊUTICA DE SUPORTE}

O principal motivo de admissão foi insuficiência respiratória, o que está de acordo com a fisiopatologia e curso evolutivo da doença. ${ }^{9} \mathrm{Na}$ ausência de terapêutica específica eficaz (antiviral ou outra), a terapêutica de suporte assume especial importância. Na primeira iteração das guidelines da Sociedade Portuguesa de Cuidados Intensivos, que um de nós co-autorou, ${ }^{1}$ defendeu-se a entubação precoce e uma estratégia ventilatória invasiva em tudo semelhante à classicamente utilizada na síndrome de dificuldade respiratória do adulto (ARDS):

1. Estratégia de ventilação baseada no protocolo da ARDS Network [volume corrente de $6 \mathrm{~mL} / \mathrm{kg}$ de peso corporal ideal com limite superior para pressões de plateau $<30 \mathrm{cmH}_{2} \mathrm{O}$ ] com frequência respiratória mínima para $\mathrm{pH}>$ 7,30 e associada a driving pressure $<15$ $\mathrm{cmH}_{2} \mathrm{O}$;

2. Tabela de PEEP baixa ou alta (com eventuais manobras de recrutamento);

3. Decúbito ventral precoce se relação $\mathrm{PaO}_{2} / \mathrm{FiO}_{2}<150$ mmHg por períodos mínimos de 16 horas; e

4. Bloqueadores neuromusculares por $\leq 48$ horas se relação $\mathrm{PaO}_{2} / \mathrm{FiO}_{2}<150 \mathrm{mmHg}$ ou se dessincronia frequente. 
A experiência prática e nova evidência que permitiu compreender os processos fisiopatológicos subjacentes à COVID-19 fizeram mudar esta estratégia inicial. Assim passamos a considerar a existência de dois fenótipos ${ }^{10,11}$ diferentes da expressão pulmonar da COVID-19 (Tabela 2): fenótipo L (pneumonite associada à COVID-19) e fenótipo H (ARDS "clássico").

Assim, em doentes com fenótipo L com evolução indolente e sem evidência de dispneia ou de significativo aumento do trabalho respiratório, mas com falência da oxigenoterapia convencional $\left(\mathrm{SpO}_{2}<90 \%\right.$ com $\mathrm{FiO}_{2}$ $\geq 40 \%$ ) passámos a fazer um ensaio de oxigenoterapia de alto fluxo por cânulas nasais (HFNO) ou ventilação mecânica não invasiva (VNI), utilizando continuous positive airway pressure, o que permitiu frequentemente evitar a ventilação mecânica invasiva. Sincronamente passamos a incentivar o auto-ventral (posicionamento em decúbito ventral do doente acordado) em associação à VNI ou HFNO para melhorar o ratio $\mathrm{PaO}_{2} / \mathrm{FiO}_{2} \cdot{ }^{12} \mathrm{O}$ auto-ventral foi, à semelhança de outros, ${ }^{13}$ realizado pelo menos duas vezes por dia por períodos superiores a 30 minutos e até o doente manifestar cansaço/intolerância.

Assim, existiu necessidade de ventilação mecânica invasiva em $70 \%$ dos doentes, sendo a relação $\mathrm{PaO}_{2} / \mathrm{FiO}_{2}$ média à admissão de $169 \pm 37,4$, o que representa um subgrupo de doentes com significativa hipoxemia. ${ }^{14}$ A utilização menos frequente de ventral (em doentes ventilados) e PEEP máxima média mais baixa que outras casuísticas ${ }^{6}$ traduz a evolução do conhecimento na fisiopatologia previamente descrita, com fenótipo L predominante na nossa casuística (90\%). De notar que 30\% dos doentes (em especial os mais novos e colaborantes) foram geridos unicamente com VNI/HFNO e auto-ventrais como previamente descrito..$^{13}$ Ocorreu falên- cia de VNI/HFNO em apenas um doente que mais tarde veio a necessitar não apenas de ventilação mecânica invasiva como também de $\mathrm{ECCO}_{2}-\mathrm{R}$ (remoção extracorpórea de $\mathrm{CO}_{2}$ ), atestando o peso significativo da sua insuficiência respiratória crónica de base..$^{15}$

Embora uma percentagem significativa de doentes (70\%) tenha necessitado de suporte vasopressor com noradrenalina, estes correspondem essencialmente aos doentes sob ventilação mecânica invasiva, com vasoplegia decorrente de doses elevadas de analgo-sedação para redução do drive respiratório.

\section{TERAPÊUTICA MEDICAMENTOSA ESPECÍFICA}

Aquilo a que os psicólogos chamam a ilusão de controlo, que nos leva a sobrestimar o efeito das nossas ações e a inferirmos causalidade onde ela não existe, é traduzido em Medicina pela ilusão terapêutica, que conduz ao uso inapropriado, com entusiasmo injustificado, de exames e novos medicamentos. ${ }^{16} \mathrm{Em}$ alturas de crise na saúde pública, a procura de terapêuticas não comprovadas e com risco potencial, é propulsionada pelo endosso e divulgação entusiasta de figuras públicas, como foi o caso algo patético da promoção da combinação hidroxicloroquina/azitromicina pelo presidente Donald Trump e o empresário Elon Musk, sem um contraditório firme por parte das autoridades de saúde pública. ${ }^{17}$

Para mais, nesta última quinzena de abril, têm sido revelados resultados preliminares negando qualquer benefício da hidroxicloroquina na redução do shedding viral, mortalidade ou demora média em cuidados intensivos, mas aumentando substancialmente os efeitos adversos (cardiovasculares e digestivos) quando comparado com placebo. ${ }^{18}$ Por outro lado, nos últimos dias, avolumam-

TABELA 2. Fenótipos clínicos da expressão pulmonar da COVID-19.

\begin{tabular}{|c|c|c|}
\hline & $\begin{array}{l}\text { FENÓTIPO L } \\
\text { PNEUMONITE ASSOCIADA À COVID-19 }\end{array}$ & $\begin{array}{l}\text { FENÓTIPO H } \\
\text { ARDS "CLÁSSICO" }\end{array}$ \\
\hline CARACTERÍSTICAS & $\begin{array}{l}\text { baixa elastância (alta compliance) } \\
\text { baixa ventilação/perfusão } \\
\text { baixo peso pulmonar } \\
\text { baixa recrutabilidade pulmonar }\end{array}$ & $\begin{array}{l}\text { alta elastância (baixa compliance) } \\
\text { alto shunt } \\
\text { alto peso pulmonar } \\
\text { alta recrutabilidade pulmonar }\end{array}$ \\
\hline CLÍNICA & $\begin{array}{l}\text { hipoxemia silenciosa } \\
\text { (sem dispneia) }\end{array}$ & $\begin{array}{l}\text { hipoxemia sintomática } \\
\text { (dispneia e aumento do trabalho respiratório) }\end{array}$ \\
\hline $\begin{array}{l}\text { PADRÃO } \\
\text { RADIOLÓGICO }\end{array}$ & $\begin{array}{l}\text { infiltrados tipo vidro despolido focais ou multifocais peri- } \\
\text { féricos de predomínio basal (e, mais tardiamente, padrão } \\
\text { de crazy-paving) }\end{array}$ & $\begin{array}{l}\text { confluência de consolidações com afeção predominante das } \\
\text { zonas dependentes }\end{array}$ \\
\hline FISIOPATOLOGIA & $\begin{array}{l}\text { alteração da ventilação/perfusão, com redução da per- } \\
\text { fusão pulmonar (vasoplegia e microtromboses do leito } \\
\text { vascular pulmonar) mas com quase normal quantidade de } \\
\text { pulmão ventilado (com aumento do drive respiratório con- } \\
\text { dicionando aumento do volume-minuto) }\end{array}$ & $\begin{array}{l}\text { shunt intrapulmonar, por preenchimento alveolar por exsu- } \\
\text { dado inflamatório com redução da quantidade de pulmão } \\
\text { normalmente ventilado (baby lung) decorrente de aumento } \\
\text { da permeabilidade da membrana alvéolo-capilar e possível } \\
\text { P-SILI }\end{array}$ \\
\hline
\end{tabular}

ARDS - síndrome de dificuldade respiratória do adulto; P-SILI - patient-self inflicted lung injury 
-se esperanças num resultado positivo com o antiviral remdesivir - especulando-se a aprovação iminente pela Food and Drug Administration - em virtude de um estudo positivo que promove uma melhoria sintomática mais rápida bem como uma redução do tempo de ventilação mecânica, mas sem interferir com a redução da carga viral ou a mortalidade. ${ }^{19}$ Apesar das diligências efetuadas por nós mesmos e pela Farmácia Hospitalar não tivemos acesso ao fármaco, por o fabricante (Gilead Sciences, Inc.) estar a transitar de um programa de acesso baseado num modelo de autorização individual para uso compassivo para um programa de acesso expandido.

No início desta campanha, os doentes chegavam-nos do Atendimento Permanente e Internamento, com um pacote terapêutico quase uniforme, incluindo a hidroxicloroquina (atraente por ser barata e todos termos experiência de utilização noutras indicações clínicas), antivirais como o lopinavir/ritonavir (já utilizados sem sucesso nas epidemias do SARS, MERS e Ébola) e, ainda, sob antibioterapia com ceftriaxone/azitromicina e frequentemente sob corticoterapia.

As mais recentes guidelines publicadas pelo prestigiado National Institute of Health ${ }^{20}$ e pela própria Sociedade Portuguesa de Cuidados Intensivos e Grupo Infeção e Sépsis ${ }^{21}$ reafirmam que não existe evidência científica que suporte o uso de qualquer antiviral ou terapêutica imunomodeladora em doentes com formas graves de COVID-19, desaconselhando igualmente o uso de antibioterapia de rotina na ausência de qualquer indicação formal, ficando a utilização de corticoterapia reservada a doentes com critérios de ARDS ou choque refratário.

Na nossa casuística todos os doentes foram submetidos a terapêutica com hidroxicloroquina, que se encontrava indicada à data pelas normas da Direção Geral da Saú$\mathrm{de}^{22}$ e guidelines nacionais para cuidados intensivos; ${ }^{1}$ é de notar a elevada prevalência de interrupção desta terapêutica justificada predominantemente por alterações disrítmicas. ${ }^{23}$ Em relação à antibioticoterapia, numa percentagem elevada de doentes foi iniciada (ou mantida) terapêutica empírica à admissão ou durante o internamento por presunção de sobreinfeção bacteriana, o que é frequente nesta população específica de doentes críticos. ${ }^{24}$ Por fim, em 8 doentes cujos marcadores inflamatórios laboratoriais tiveram um surto de agravamento a partir do oitavo dia (coincidente com agravamento da insuficiência respiratória), foi introduzida corticoterapia, que julgamos ter beneficiado a duração do tempo de ventilação invasiva em acordo com o verificado em outros estudos Chineses. ${ }^{25,26}$

\section{OUTRAS COMPLICAÇÕES E SUAS TERAPÊUTICAS}

Em relação às complicações de notar que 70\% dos doentes (correspondendo aos doentes ventilados), apresentou quadro de delirium com necessidade de medicação com dexmedetomidina e/ou neurolépticos, o que se tem demonstrado frequente em doentes críticos com COVID-19, ${ }^{27}$ em virtude quer do efeito direto do vírus quer de fatores relacionados com a estratégia sedativa e ausência de medidas preventivas (nomeadamente presença de familiares). A necessidade de suporte transfusional ocorreu no doente em $\mathrm{ECCO}_{2}-\mathrm{R}$ por hemorragia retroperitoneal resolvida com terapêutica de suporte, que não é infrequente neste grupo de doentes, ${ }^{28}$ em especial se idosos.

\section{OUTCOMES}

À data da recolha de dados (30 de abril) não se verificaram óbitos, com $90 \%$ dos doentes com alta da UCIP (tempo de internamento em $\mathrm{UCl}$ de 8,4 \pm 4,1 dias) e $80 \%$ com alta hospitalar, o que representa um resultado de outcome excelente e atípico. Sendo o grau de gravidade e estratégia terapêutica sobreponíveis ao das séries mundiais, $2,6,7$ estes resultados traduzem provavelmente os melhores outcomes possíveis nestes doentes quando se aplicam todos os recursos humanos e tecnológicos fora de um ambiente de catástrofe. Por fim será de notar que durante este período não só os doentes COVID-19 foram adequadamente tratados como se manteve a restante atividade da UCIP (com admissão de 24 doentes não COVID-19), sem casos de infeção cruzada por SARS-CoV-2 entre doentes, e se obteve o objetivo de ausência de casos de infeção por SARS-CoV-2 entre profissionais de saúde.

\section{CUSTOS E REEMBOLSOS}

Em preparação da presente campanha calculámos que o custo médio diário de um doente em cuidados intensivos sob ventilação mecânica invasiva orçava os $1600 €$, excluindo-se neste preço outras técnicas como as técnicas de suporte de função renal, o suporte de vida extracorporal, bem como o financiamento do indispensável upgrade do ratio de enfermagem (por doente).

O reembolso destes custos foi a posteriori negado, uma vez que os doentes que tratámos acorreram por sua iniciativa ao nosso AP, não foram diretamente referenciados pela linha SNS24, como era entendimento do Ministério da Saúde. De qualquer forma nunca seriam superiores em doentes ventilados por mais de 4 dias a $13000 €$ pela totalidade do internamento (demora média na UCIP 8,4 dias, duração média do internamento 18 dias). 


\section{CONCLUSÃO}

Numa UCIP amadurecida (com mais de 40 anos e uma equipa bastante estável e experimentada) muitos de nós fomos apanhados com idades rondando os 65 anos. Se o mais grave fator de risco para um mau prognóstico do COVID-19 é claramente a pobreza segue-se-Ihe a idade. ${ }^{26}$

No entanto, todos os que preferimos não ocupar este período a prestar cuidados à distância ou a fazer teleconsultas, cedo compreendemos que o stress físico e psicológico seria bem superior senão respondessemos à chamada, quais Dr. Rieux na novela A Peste de Albert Camus: I have no idea what's awaiting me, or what will happen when this all ends. For the moment I know this: there are sick people and they need curing.

Perante o inexplicável equívoco no acordo de prestação do serviço a doentes COVID-19 entre a hospitalização privada e o SNS, com abandono do discurso oficial de um sistema de saúde misto com complementaridade entre os setores público e privado - tantas vezes evocado como vantajoso - para um regresso à fase em que a Ministra assume apenas o pelouro do sistema público, era imperativo escrevermos este artigo.

Não sabemos qual o futuro que a pandemia nos reserva, nem tão pouco o volume de doentes que continuaremos a tratar, agora que as seguradoras equacionam poder financiar parcialmente os custos do internamento, mas se não puséssemos em papel esta nossa experiência, ela iria desvanecer-se na espuma do tempo como se parte do equívoco se tratasse, sem honrar a motivação e a prestação exemplar de todos os que participamos.

NOTA: Importa realçar que, numa área do conhecimento em que nova informação cresce exponencialmente à semana, este artigo e a informação nela contida se reporta à data de 6 de maio de 2020, dia em que foi submetido para publicação.

\section{AGRADECIMENTOS/ ACKNOWLEDGEMENTS}

Ana Bernardo, Ana Cardoso, Ana Herdade, Anabela Mina, Ana Paula Pereira, Ana Silva, Bárbara Freitas, Beatriz Rey, Carla Borges, Carla Paiva, Catarina Silva, Cátia Marques, Célia Costa, Diana Costa, Filipa Barbosa, Filipe Gonzalez, Helena Carvalho, Inês Espírito Santo, Iria Cardoso, Lurdes Venâncio, Luzia Borges, Jéssica Postiço, João Lopes, João Pires, Joaquim Simões, José Pinheiro, José Viegas, Luís Castro, Marco Pinto, Maria Adelaide Martins, Maria da Luz Machado, Mariana San- tos, Marta Eizaguirre, Nelson Santos, Octávio Azevedo, Patrícia Baptista, Raquel Cavaco, Ricardo Marques, Rita Mendonça, Roberto Nóbrega, Rute Coutinho, Rute Jesus, Susana Silva, Tomás Lamas, Vira Kovalchuk.

\section{RESPONSABILIDADES ÉTICAS}

CONFLITOS DE INTERESSE: Os autores declaram a inexistência de conflitos de interesse na realização do presente trabalho.

FONTES DE FINANCIAMENTO: Não existiram fontes externas de financiamento para a realização deste artigo.

CONFIDENCIALIDADE DOS DADOS: Os autores declaram ter seguido os protocolos da sua instituição acerca da publicação dos dados de doentes.

PROTEÇÃO DE PESSOAS E ANIMAIS: Os autores declaram que os procedimentos seguidos estavam de acordo com os regulamentos estabelecidos pelos responsáveis da Comissão de Investigação Clínica e Ética e de acordo com a Declaração de Helsínquia da Associação Médica Mundial.

PROVENIÊNCIA E REVISÃO POR PARES: Não comissionado; revisão externa por pares.

\section{ETHICAL DISCLOSURES}

CONFLICTS OF INTEREST: The authors have no conflicts of interest to declare.

FINANCIAL SUPPORT: This work has not received any contribution, grant or scholarship.

CONFIDENTIALITY OF DATA: The authors declare that they have followed the protocols of their work center on the publication of data from patients.

PROTECTION OF HUMAN AND ANIMAL SUBJECTS: The authors declare that the procedures followed were in accordance with the regulations of the relevant clinical research ethics committee and with those of the Code of Ethics of the World Medical Association (Declaration of Helsinki).

PROVENANCE AND PEER REVIEW: Not commissioned; externally peer reviewed.

\section{REFERÊNCIAS}

1. Mendes JJ, Mergulhão P, Froes F, Paiva JA, Gouveia J. Recommendations from the Sociedade Portuguesa de Cuidados Intensivos and Infection \& Sepsis Group for intensive care approach to COVID-19. Rev Bras Ter Intensiva. 2020;32:210 .

2. Wang D, Hu B, Hu C, Zhu F, Liu X, Zhang J, et al. Clinical Characteristics of 138 Hospitalized Patients With 2019 Novel Coronavirus-Infected Pneumonia in Wuhan, China. JAMA. 2020;323:1061-9. doi: 10.1001/jama.2020.1585. 
3. World Health Organization. Coronavirus disease 2019 (COVID-19) Situation Report. Geneve: WHO; 2020.

4. Richardson S, Hirsch JS, Narasimhan M, Crawford JM, McGinn T, Davidson KW, et al. Presenting Characteristics, Comorbidities, and Outcomes Among 5700 Patients Hospitalized With COVID-19 in the New York City Area. JAMA. 2020 (in press). doi: 10.1001/jama.2020.6775.

5. Koven S. They Call Us and We Go. N Engl J Med. 2020;382:1978-9. doi: 10.1056/NEJMp2009027.

6. Grasselli G, Zangrillo A, Zanella A, Antonelli M, Cabrini L, Castelli A, et al. Baseline Characteristics and Outcomes of 1591 Patients Infected With SARS-CoV-2 Admitted to ICUs of the Lombardy Region, Italy. JAMA 2020; 323:1574-81. doi: 10.1001/jama.2020.5394.

7. Arentz M, Yim E, Klaff L, Lokhandwala S, Riedo FX, Chong M, et al. Characteristics and Outcomes of 21 Critically III Patients With COVID-19 in Washington State. JAMA. 2020;323:16124. doi: 10.1001/jama.2020.4326.

8. Rosenbaum L. The Untold Toll - The Pandemic's Effects on Patients without Covid-19. N Engl J Med. 2020 (in press). doi: 10.1056/NEJMms2009984.

9. Siddiqi HK, Mehra MR. COVID-19 IIIness in Native and Immunosuppressed States: A Clinical-Therapeutic Staging Proposal. J Heart Lung Transplant. 2020;39:405-7. doi: 10.1016/j. healun.2020.03.012.

10. Gattinoni L, Chiumello D, Caironi P, Busana M, Romitti F, Brazzi L, et al. COVID-19 pneumonia: different respiratory treatment for different phenotypes? Intensive Care Med. 2020 (in press). doi: 10.1007/s00134-020-06033-2.

11. Gattinoni L, Coppola S, Cressoni M, Busana M, Chiumello D. Covid-19 Does Not Lead to a "Typical" Acute Respiratory Distress Syndrome. Am J Respir Crit Care Med. 2020 (in press). doi: 10.1164/rccm.202003-0817LE.

12. Sun Q, Qiu H, Huang M, Yang Y. Lower mortality of COVID-19 by early recognition and intervention: experience from Jiangsu Province. Ann Intensive Care. 2020;10:33. doi: 10.1186/ s13613-020-00650-2.

13. Ding L, Wang L, MaW, He H. Efficacy and safety of early prone positioning combined with HFNC or NIV in moderate to severe ARDS: a multi-center prospective cohort study. Crit Care. 2020;24:28. doi: 10.1186/s13054-020-2738-5.

14. Bellani G, Laffey JG, Pham T, Fan E, Brochard L, Esteban A, et al. Epidemiology, Patterns of Care, and Mortality for Patients with Acute Respiratory Distress Syndrome in Intensive Care Units in 50 Countries. JAMA. 2016;315:788-800.

15. MacLaren G, Fisher D, Brodie D. Preparing for the Most Critically III Patients With COVID-19: The Potential Role of Extracorporeal Membrane Oxygenation. JAMA. 2020 (in press). doi: 10.1001/jama.2020.2342.

16. Casarett D. The Science of Choosing Wisely-Overcoming the Therapeutic Illusion. N Engl J Med. 2016;374:1203-5.

17. Liu M, Caputi TL, Dredze M, Kesselheim AS, Ayers JW. Internet Searches for Unproven COVID-19 Therapies in the United States. JAMA Intern Med. 2020 (in press). doi: 10.1001/ jamainternmed.2020.1764.

18. Borba MGS, Val FFA, Sampaio VS, Alexandre MAA, Melo GC, Brito M, et al. Effect of high vs low doses of chloroquine diphosphate as adjunctive therapy for patients hospitalized with severe acute respiratory syndrome coronavirus 2 (SARS-CoV-2) infection: A Randomized Clinical Trial. JAMA Netw Open. 2020;3:e208857.

19. Wang Y, Zhang D, Du G, Du R, Zhao J, Jin Y, et al. Remdesivir in adults with severe COVID-19: a randomised, double-blind, placebo-controlled, multicentre trial. Lancet. 2020 (in press). doi: 10.1016/S0140-6736(20)31022-9.

20. National Institute of Health (NIH). COVID-19 Treatment Guidelines 2020 [Available from: https://www.covid19treatmentguidelines.nih.gov/overview/.

21. Mendes JJ, Mergulhão P, Paiva JA, Gouveia J. Actualização da Recomendações COVID-19 2020 [consultado 2020-05-01] Disponível em: https://www.spci.pt/media/covid-19/COVID_19_R_20200331.pdf.

22. Direçao Geral de Saúde. COVID-19: Abordagem do Doente com Suspeita ou Infeção por SARS-CoV-2 (004/2020). 23/03/2020 ed2020. Lisboa: DGS; 2020.

23. TangW, CaoZ, Han M,Wang Z, Chen J, SunW,etal. Hydroxychloroquine in patients with COVID-19: an open-label, randomized, controlled trial. medRxiv. 2020:2020.04.10.20060558.

24. Guan WJ, Ni ZY, Hu Y, Liang WH, Ou CQ, He JX, et al. Clinical Characteristics of Coronavirus Disease 2019 in China. N Engl J Med. 2020 (in press). doi: 10.1056/NEJMoa2002032.

25. Wang Y, Jiang W, He Q, Wang C, Wang B, Zhou P, et al. Early, low-dose and short-term application of corticosteroid treatment in patients with severe COVID-19 pneumonia: single-center experience from Wuhan, China. medRxiv. 2020:2020.03.06.20032342.

26. Wu C, Chen X, Cai Y, Xia J, Zhou X, Xu S, et al. Risk Factors Associated with Acute Respiratory Distress Syndrome and Death in Patients with Coronavirus Disease 2019 Pneumonia in Wuhan, China. JAMA Intern Med. 2020 (in press). doi: 10.1001/jamainternmed.2020.0994.

27. Kotfis K, Williams Roberson S, Wilson JE, Dabrowski W, Pun BT, Ely EW. COVID-19: ICU delirium management during SARS-CoV-2 pandemic. Critical Care. 2020;24:176. doi: 10.1186/s13054-020-02882-X.

28. Morales-Quinteros L, Del Sorbo L, Artigas A. Extracorporeal carbon dioxide removal for acute hypercapnic respiratory failure. Ann Intensive Care. 2019;9:79. doi: 10.1186/s13613019-0551-6. 